\title{
The influence of local anesthetic solutions storage on tissue inflammatory reaction
}

\author{
Luciana-Aranha Berto, Francisco-Carlos Groppo, Juliana-Cama Ramacciato, Giovana Tófoli, Maria-Cristi- \\ na Volpato, José Ranali, Pedro-Duarte Novaes, Rogério-Heládio-Lopes Motta
}

Department of Pharmacology, Anesthesiology and Therapeutics - São Leopoldo Dental School, Brazil

Correspondence:

Department of Pharmacology,

Anesthesiology and Therapeutics

São Leopoldo Dental School, Brazil.

Rua José Rocha Junqueira, 13 Bairro Abolição

Campinas $-S P$

CEP: 13045-755 BRAZIL

motta@sedcare.com.br

Received: 21-07-2009

Accepted: 06-03-2010

\begin{abstract}
Berto LA, Groppo FC, Ramacciato JC, Tófoli GR, Volpato MC, Ranali J, Novaes PD, Motta RHL. The influence of local anesthetic solutions storage on tissue inflammatory reaction. Med Oral Patol Oral Cir Bucal. 2011 Jan 1;16 (1):e83-8.

http://www.medicinaoral.com/medoralfree01/v16i1/medoralv16ilp83.pdf
\end{abstract}

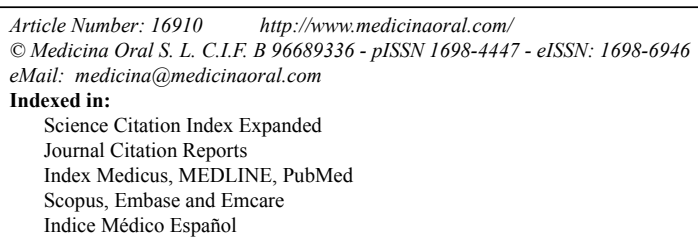

\begin{abstract}
Objective: This study aimed to analyze the influence of storage conditions of local anesthetic solutions in the inflammatory reaction after injection in rats.

Study design: Twenty-four rats received in their oral mucosa the injection of $2 \%$ lidocaine with epinephrine 1:100.000 solutions (LA) submitted to the following storage conditions during a twelve-month period: G1 - inside the original packaging, in refrigerator $\left(5 \pm 1^{\circ} \mathrm{C}\right)$; $\mathrm{G} 2$ - inside the original box, under light shelter, at room temperature; G3 - outside the original box at room temperature (exposed to artificial light for 12 hours/day) and G4 - brand new solution. For the controls tests, $0.9 \%$ sodium chloride solution was injected in the opposite side. After 6 and 24 hours, three animals of each group were sacrificed and their maxilla along with the soft tissue were removed and submitted to histological analysis (HE).

Results: The $\mathrm{pH}$ of LA was measured before and after the storage period and no statistically differences were observed between G1 and G4, but both were different from G2 and G3. All the scores of the testing solutions were higher than their respective negative controls, except for G1 at 6 hours. The order of the scores of inflammation after 6 hours was $\mathrm{G} 3>\mathrm{G} 4>\mathrm{G} 2=\mathrm{G} 1$. After 24 hours the order was $\mathrm{G} 3>\mathrm{G} 2>\mathrm{G} 1>\mathrm{G} 4$.

Conclusion: The study showed that the method of storage can influence the $\mathrm{pH}$ and the level of inflammatory reaction after the injection of $2 \%$ lidocaine with epinephrine 1:100.000.
\end{abstract}

Key words: Local anesthetics, storage conditions, lidocaine, rats. 


\section{Introduction}

Local anesthetics (LA) are the safest and the most effective drugs for the control and management of pain in medicine and dentistry (1). The currently available solutions can be safely administered showing few and rare adverse effects such as tissue irritation or allergic reactions. In fact, complications associated with LA are rarely reported. In addition, almost all available solutions have shown efficacy, providing rapid onset of local anesthesia with adequate duration (2).

However, in some situations, LA can cause local tissue irritation resulting in inflammatory reaction, and consequently pain during and/or after anesthesia (3). The acidity of LA is one of the main causes of those adverse effects. The $\mathrm{pH}$ varies among the different anesthetic solutions due to many factors, being the LA with vasoconstrictors generally the most acid solutions (1).

Solutions without vasoconstrictors usually show $\mathrm{pH}$ (ranging between 5.5 and 7) close to the physiologic $\mathrm{pH}$. LA with vasoconstrictor has lower $\mathrm{pH}$ (between 3.5 and 5.5) than the plain LA solutions being the low $\mathrm{pH}$ an important factor to avoid the oxidation of the vasoconstrictor $(4,5)$. However, very low $\mathrm{pH}$ could result in tissue irritation and the very acid solutions are likely the primary source of pain (6).

The time and the storage conditions could contribute to the deterioration of LA solutions and significantly decrease the $\mathrm{pH}(7,8)$ affecting the vasoconstrictor concentration, which interferes in the LA performance $(9,10)$.

The present study evaluated the tissue reaction induced in the oral mucosa of rats by injecting solutions of LA submitted to three different storage methods.

\section{Materials and Methods}

\section{- Animals and drugs}

Twenty-four male Wistar rats (Rattus norvegicus, albinus), 60 days of age and weighing $175 \mathrm{~g} \pm 25 \mathrm{~g}$, were obtained from CEMIB-UNICAMP (Centro de Bioterismo - ICLAS Monitoring/Reference Center, Campinas, Brazil) where they were maintained under aseptic conditions. The protocol was approved by the Animal Ethical Committee - Institute of Biology - University of Campinas, Sao Paulo, Brazil (\#504-1).

- Storage conditions and surgical procedure

The 2\% lidocaine with epinephrine 1:100.000 (Lidocaina 100 - Alphacaine ${ }^{\circledR}$ - DFL, Brazil) anesthetic solutions were in the last month of their expiration date and they were previously submitted to three different storage methods during a twelve-month period.

The local anesthetic solutions (LAS) were divided into 4 groups: Group 1, inside the original box, in a refrigerator, at average temperature of $5^{\circ} \mathrm{C}$; Group 2, inside the original box at room temperature, under light shelter; Group 3, outside the original box, at room temperature (average temperature $=21.9 \mathrm{oC}$ ), exposed to the artificial light during 12 hours/day. The Group 4 was composed by recently manufactured solution, not submitted to storage.

Slightly general anesthesia was induced by an injection of a sodium thiopental solution (Thiopentax ${ }^{\circledR}$ - Cristália, São Paulo, Brazil) in the concentration of $40 \mathrm{mg} / \mathrm{kg} / \mathrm{i}$.p. before the administration of LAS.

The LAS tested $(0.1 \mathrm{~mL})$ were injected in the mucosa of the first upper-right molar of rats (six rats/group). $0.1 \mathrm{~mL}$ of a saline solution $(\mathrm{NaCl} 0.9 \%)$ was injected in the mucosa of the opposite side of all animals (negative control). After six and 24 hours, three animals of each group were killed and the samples (maxilla and the soft tissue adhered) were removed.

Before the injections, the $\mathrm{pH}$ of the solutions was measured by using an ORION ${ }^{\circledR}$ model $290 \mathrm{~A}$ pHmeter, with a LAZAR BNC microelectrode.

- Histological Analysis

The samples were fixed with $10 \%$ formalin solution and five cross-sections ( $6 \mu \mathrm{m}$ thick, one each $40 \mu \mathrm{m}$ of depth) were obtained from each animal. The samples were stained with hematoxylin and eosin.

The samples were blinded submitted to qualitative analysis in order to evaluate the intensity of leucocitary infiltration and/or any possible necrosis area. A preliminary pilot study conduced according other previous studies allowed the use of a qualitative score of the local tissue inflammation (11-13). The soft tissue and bone near the injection site were analyzed. The score was defined based on the following descriptions: (1) no inflammatory infiltration, (2) mild inflammatory infiltration, (3) moderate inflammatory infiltration, (4) intense inflammatory infiltration and (5) intense inflammatory infiltration with necrosis area.

- Statistical analysis

The $\mathrm{pH}$ obtained after one year in each storage method (groups 1 to 3) was compared to the $\mathrm{pH}$ obtained in group 4 by ANOVA and Dunnet tests. The data regarding inflammatory infiltration were submitted to the Kruskal-Wallis test for the comparison among different groups, and Wilcoxon test to compare the inflammatory infiltration observed in the right (test solutions) and left (negative control) sides. Differences of a $\mathrm{P}$ value of less than 0.05 were considered statistically significant.

\section{Results}

Figure 1 show the $\mathrm{pH}$ values obtained from the anesthetics of Groups 1 to 4.

The comparison (ANOVA, Tukey test) of the $\mathrm{pH}$ values showed no statistically significant differences between groups 1 and $4(\mathrm{p}>0.05)$. However, the $\mathrm{pH}$ of both groups 1 and 4 were significantly higher $(\mathrm{p}<0.01)$ than groups 2 and 3 , being the $\mathrm{pH}$ of group 2 significantly higher than group $3(\mathrm{p}<0.05)$. 


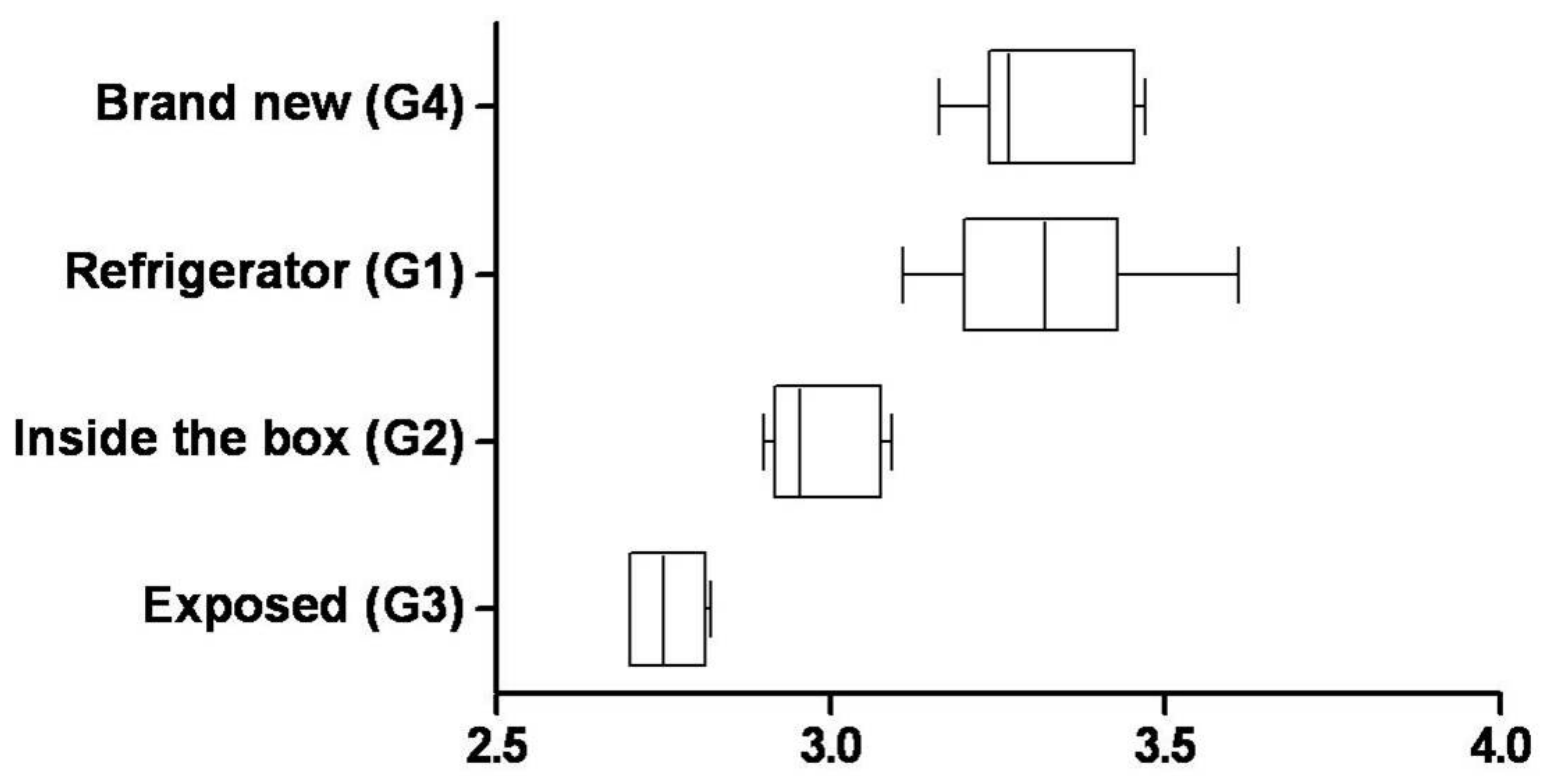

Fig. 1. PH of the tested anesthetic solutions. (Central line: median; Box: 1st and 3rd quartiles; Whisker: max and min values).

Table 1. Median (lower and upper quartiles) of the inflammatory scores for all groups in both periods of time.

\begin{tabular}{lllll}
\hline & 6 hours & \multicolumn{3}{l}{24 hours } \\
\hline Groups & Test & Control & Test & Control \\
\hline Group 1 (Refrigerator) & $2(2-3)$ & $2(2-2)$ & $3(2-3)$ & $2(2-2)$ \\
Group 2 (Box) & $3(2-3)$ & $2(2-2.5)$ & $3(3-3.5)$ & $2(2-2)$ \\
Group 3 (Exposed) & $4(3-4)$ & $2(2-2)$ & $4(3-4)$ & $2(2-2.5)$ \\
Group 4 (Brand new) & $3(2.5-3)$ & $2(2-2)$ & $3(2-3)$ & $2(2-2)$ \\
\hline
\end{tabular}

The table 1 shows the scores obtained for the inflammatory cells after 6 and 24 hours of the administration of the anesthetics (Groups 1 to 4). No statistically significant differences were observed among the scores of the negative controls (Kruskal-Wallis, $p>0.05$ ) at 6 or 24 hours. In addition, all the scores of the testing solutions were higher than their respective negative controls (Wilcoxon, $\mathrm{p}<0.05$ ), except for Group 1 at 6 hours (Wilcoxon, $\mathrm{p}=0.0679$ ).

Considering the six hours time, Group 3 showed the highest score among the other solutions and controls (Kruskal-Wallis, $\mathrm{p}<0.05$ ). There were no statistically significant differences (Kruskal-Wallis, $\mathrm{p}>0.05$ ) among the other groups.

No statistically significant differences (Kruskal-Wallis, $\mathrm{p}>0.05$ ) were found among the tested groups at the 24 hours period, but all tested solution showed higher inflammatory scores in comparison with their respective controls.
The level one of the inflammatory score was not found in the present study, because even the saline solution caused at least a mild inflammatory reaction. The figures 2 and 3 show the inflammatory reaction induced by each anesthetic solution in both periods of time.

\section{Discussion}

The inflammatory reaction induced by LAS was previously observed by De Carvalho et al. (13) and Ribeiro et al. (3). These studies observed polyethylene tubes containing absorbent-paper cones that were soaked in different anesthetic solutions, being subcutaneously implanted in the back of rats. This method could promote a more prolonged contact between LAS and tissues, easily allowing the localization of the implanted area. However, the oral mucosa close to the upper-first molar, as used in the present study, could better simulate the inflammatory reaction in the oral sites. The analysis of the results obtained in the control sides alone shows 


\section{HOURS}

\section{Group 1}

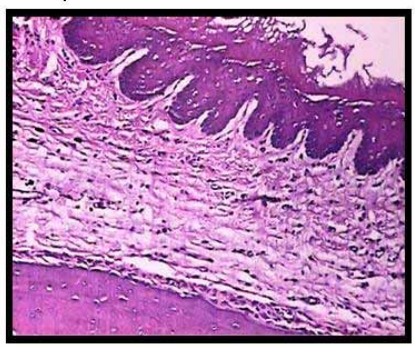

Group 3

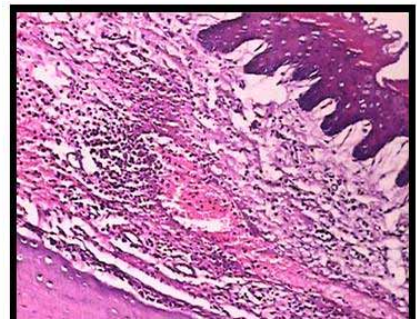

Fig. 2. Histological slides of soft tissue of rats after 6 hours of the injection of the anesthetic solutions (Groups 1, 2, 3 and 4). HE, magnification x10.

\section{Group 2}

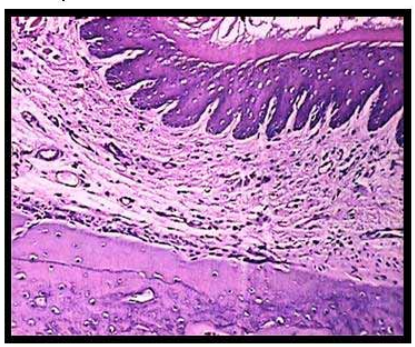

\section{Group 4}

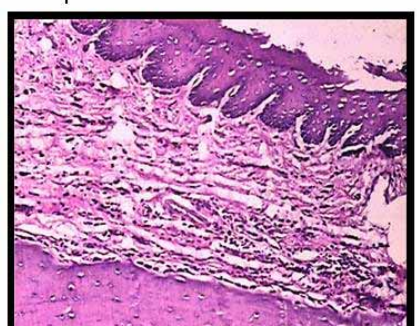

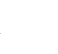

\author{
政
}


the homogeneity and the standardization of the method used in the present study, allowing a precise comparison of the effect of the LAS.

Previous studies showed lidocaine as the least irritating local anesthetic when compared to the other LAS commonly used in dentistry $(3,13)$. Thus, we decide to observe this local anesthetic in our study.

Wakamatsu (14) observed that $2 \%$ lidocaine with or without epinephrine did not change the postextraction wound healing process. However, in the present study we observed that the lidocaine solutions caused higher levels of inflammation when comparing to their respective controls. The vasoconstrictor (epinephrine 1:100,000), which causes slow absorption and elimination of the LAS, could be the responsible for this difference.

Another explanation for this finding is that lidocaine (and other anesthetic agents), in clinical doses, has antiinflammatory actions, thus inhibiting leukocyte adhesion, migration and phagocytosis, as well as inflammatory mediators synthesis, vascular hyperpermeability and edema formation (15). Our results, nevertheless, showed that the lidocaine solutions caused higher levels of inflammation when comparing to their respective controls except for Group 1 at 6 hours. This increased inflammatory reaction could be attributed to the $\mathrm{pH}$ of the LAS studied.

The $\mathrm{pH}$ of commercial LAS added with sympathomimetic amines (epinephrine, norepinephrine, levonordephrin and phenylephrine) usually varies from 3.5 to 5.5 (4), being these low $\mathrm{pH}$ values necessary to reduce the oxidation of these sympathomimetic amines (5). In our study, the measurement of the $\mathrm{pH}$ of LAS before their administration revealed that all of them were acid. The mean $\mathrm{pH}$ of all solutions was below 3.5 , being the LAS conserved at room temperature inside the box and those exposed to the light the most acid (pH below 3.0) solutions. Although these values could be considered acceptable, they could also be a strong suggestion of the chemical deterioration of the solution, particularly of the vasoconstrictor.

It is well established that certain storage conditions can alter the $\mathrm{pH}$ of the LAS $(7,9,10,16,17)$. The $\mathrm{pH}$ change is usually induced by the oxidation of the sulfites, which are used as antioxidants, into sulphates, causing protons liberation and resulting in $\mathrm{pH}$ decrease $(18,19)$. A fast reduction of the vasoconstrictor concentration and $\mathrm{pH}$ decrease $(7,8)$ by ultraviolet and infrared rays were observed when LAS were exposed to the sun light. The $\mathrm{pH}$ decrease was also observed in the present study, while the refrigerator kept the $\mathrm{pH}$ stable for one year at least. The low $\mathrm{pH}$ reflected in the inflammatory levels observed. Previous studies related adverse effects due to the use of acid and/or deteriorated solutions ranging from a slight burn sensation to a severe tissue inflam- mation (20). These effects can cause discomfort and pain during the injection, and retard the beginning of the anesthesia $(1,4,5)$. These finds are compatible with the results of the present study since the LAS expose to light and/or room temperature (Groups 2 and 3) caused more intense inflammatory reaction than the solutions stored in the refrigerator.

To the date any study was found in the literature showing the quality of the local anesthetic solutions utilized by the Brazilian dentists. Although the LAS are the drugs most used in dentistry, there is little information about the best way to storage them. Gerke et al. (8) showed a decreased epinephrine content when local anesthetic cartridges were exposed to sunlight, and recommended the professionals to avoid the sunlight exposition of the local anesthetics cartridges. This observation is corroborated by the results of the present study since the LAS stored in the refrigerator $\left( \pm 5^{\circ} \mathrm{C}\right)$ induced the less intense tissue reaction along with a more stable $\mathrm{pH}$.

Based on the results presented in this study, it can be concluded that the method of storage influenced the $\mathrm{pH}$ and the level of inflammatory reaction after the injection of $2 \%$ lidocaine with epinephrine 1:100.000.

\section{References References with links to Crossref-DOI}

1. Malamed SF. Local anesthetics: dentistry's most important drugs, clinical update 2006. J Calif Dent Assoc. 2006;34:971-6.

2. Hawkins JM, Moore PA. Local anesthesia: advances in agents and techniques. Dent Clin North Am. 2002;46:719-32.

3. Ribeiro PD Jr, Sanches MG, Okamoto T. Comparative analysis of tissue reactions to anesthetic solutions: histological analysis in subcutaneous tissue of rats. Anesth Prog. 2003;50:169-80.

4. Meechan JG. Why does local anaesthesia not work everytime? Dent Update. 2005;32:66-8, 70-2.

5. Murakami CS, Odland PB, Ross BK. Buffered local anesthetics and epinephrine degradation. J Dermatol Surg Oncol. 1994;20:192-5.

6. Redd DA, Boudreaux AM, Kent RB 3rd. Towards less painful local anesthesia. Ala Med. 1990;60:18-9.

7. Gerke DC, Crabb GA, Frewin DB. The effect of irradiation and heat on the content of adrenaline in commercially manufactured local anaesthetic solutions - a pilot study. Aust Dent J. 1978;23:311-3.

8. Gerke DC, Crabb GA, Frewin DB, Frost BR. The effect of storage on the activity of adrenaline in local anaesthetic solutions: an evaluation using bioassay and fluorometric techniques. Aust Dent J. 1977;22:423-7.

9. Fry BW, Ciarlone AE. Concentrations of vasoconstrictors in local anesthetics change during storage in cartridge heaters. J Dent Res. 1980;59:1163.

10. Bartfield JM, Homer PJ, Ford DT, Sternklar P. Buffered lidocaine as a local anesthetic: an investigation of shelf life. Ann Emerg Med. 1992;21:16-9.

11. Scheib SA, Garner WH. Anti-inflammatory effects of topical ocular MAXIDEX administration to rabbits following vitrectomy or lensectomy. Exp Eye Res. 2004;79:893-902.

12. Duggan D, Arnold RR, Teixeira FB, Caplan DJ, Tawil P. Periapical inflammation and bacterial penetration after coronal inoculation of dog roots filled with RealSeal 1 or Thermafil. J Endod. 2009;35:852-7.

13. De Carvalho AC, Okamoto T, Saad Neto M. [Reaction of subcutaneous connective tissue to some local anesthetics. Histological study in rats]. Rev Fac Odontol Aracatuba. 1976;5:53-61.

14. Wakamatsu T. [Effects of local anesthetics on healing process of 
extraction wound in rats with reference to effects of epinephrine]. Kokubyo Gakkai Zasshi. 1992;59:613-30.

15. Cassuto J, Sinclair R, Bonderovic M. Anti-inflammatory properties of local anesthetics and their present and potential clinical implications. Acta Anaesthesiol Scand. 2006;50:265-82.

16. Cooley RL, Lubow RM. Evaluation of effects of ultraviolet, infrared, and fluorescent light on $\mathrm{pH}$ of local anesthetic solutions. Mil Med. 1981;146:788-91.

17. Brennan PA, Morley MR, Langdon JD. A study of the effectiveness of dental $2 \%$ lignocaine local anaesthetic solution at different pH values. Br Dent J. 1987;163:158-9.

18. Hondrum SO, Ezell JH. The relationship between $\mathrm{pH}$ and concentrations of antioxidants and vasoconstrictors in local anesthetic solutions. Anesth Prog. 1996;43:85-91.

19. Ramacciato JG, Meechan JG. Recent advances in local anaesthesia. Dent Update. 2005;32:8-10, 12-4.

20. Schmidt K, Heller W, Schorer R. [Studies on the stability of local anaesthetics containing adrenaline (author's transl)]. Anaesthesist. $1976 ; 25: 342-4$

Acknowledgments

The authors thank Mr. Jorge Valério for his assistance in the manuscript preparation. 